\title{
Comparison of Cancer Burden and Nonprofit Organization Funding Reveals Disparities in Funding Across Cancer Types
}

Suneel D. Kamath, MDa; Sheetal M. Kircher, MDa,b; and Al B. Benson III, MDa,b

\section{ABSTRACT}

Background: Nonprofit organizations (NPOs) in oncology are vital for patient advocacy and funding research for rare cancers, young investigators, and innovative projects. However, some cancers may be underfunded relative to their burden. This study examined the alignment of cancer burden by histology with NPO funding for each histology. Patients and Methods: This nationwide, cross-sectional study conducted from October 2017 through February 2018 included all oncology NPOs with $>\$ 5$ million in annual revenue. Total revenue from NPOs supporting individual cancer types with the incidence, mortality, and person-years of life lost (PYLL) for each cancer type was compared using scatter plots and Pearson correlation coefficients. Correlation of expenditure types (eg, fundraising, patient education) with revenue was assessed using Pearson correlation coefficients. Effect of disease association with a stigmatized behavior (eg, lung cancer and smoking) was evaluated using descriptive statistics. Results: A total of 119 cancer-related NPOs were included, generating approximately $\$ 6$ billion in annual revenue in 2015. Cancers with the largest revenue were breast cancer ( $\$ 460$ million; $33.2 \%)$, leukemia (\$201 million; 14.5\%), pediatric cancers ( $\$ 177$ million; $12.8 \%)$, and lymphoma (\$145 million; 10.5\%). Breast cancer, leukemia, lymphoma, and pediatric cancers were all well funded compared with their incidence, mortality, and PYLL. Gastrointestinal (colorectal, pancreas, and hepatobiliary), gynecologic (ovarian, cervical, and endometrial), brain, and lung cancers were poorly funded in all 3 metrics. All cancers associated with a stigmatized behavior were poorly funded in at least 2 metrics. Increased spending on fundraising, administrative costs, patient education, and treatment was highly correlated with increased revenue (Pearson correlation coefficients all >0.92). Conclusions: NPO funding by cancer type is not proportionate with individual cancer burden on society. Disease stigma negatively impacts funding. A significant need exists to increase awareness and funding for many undersupported but common and highly lethal cancers.

J Natl Compr Canc Netw 2019;17(7):849-854 doi: $10.6004 /$ jnccn.2018.7280

aDepartment of Medicine, Division of Hematology/Oncology, Northwestern University Feinberg School of Medicine, and ${ }^{b}$ Robert H. Lurie Comprehensive Cancer Center of Northwestern University, Chicago, Illinois.

\section{Background}

Patient advocacy organizations (PAOs) are nonprofit organizations (NPOs) that work to combat a particular disease or group of diseases or support a certain patient population. These organizations and other cancerrelated NPOs can be influential through political advocacy to shape health policy, fund medical research, accelerate regulatory approval of novel therapies, and expand insurance coverage for specialized diagnostics, drugs, or devices. ${ }^{1-3}$ According to the most recent Giving $U S A$ report, health-related NPOs received $\$ 40.8$ billion in contributions in $2018 .{ }^{4}$

NPOs in oncology are vital for advocacy, research, and supporting young investigators. They advocate to political leaders and legislatures regionally and nationally, ${ }^{1}$ raise funds for cancer research in the basic and applied sciences and for clinical research, and make concerted efforts to support young, early-career investigators, such as the Stand Up To Cancer Innovative Research Grants program.

Although there has been much investigation into potential financial conflicts of interest from NPOs and PAOs accepting contributions from for-profit corporations, ${ }^{2,3,5,6}$ little is known about the distribution of funding for NPOs classified by the cancer type they support compared with the burden of each cancer type on society. It is possible that funding of NPOs increases proportionally with the incidence and number of deaths caused by the type of cancer those organizations support. It is also likely that other factors, such as public awareness, advertising, disease stigma, or political influences, can skew funding toward certain malignancies.

Some data show that individual donors are largely unaware of which medical causes are well supported and which are underfunded, but if informed of these disparities, the public can attempt to compensate for them. ${ }^{7}$ A study in the United Kingdom that surveyed 401 members of the general population found that respondents

See JNCCN.org for supplemental online content. 
grossly overestimated British government funding for cancer research compared with other medical research funding. After respondents were made aware of this or when asked about hypothetical cuts in governmental cancer research funding, they stated that they would increase donations to cancer research by $18 \%$ to compensate. ${ }^{8}$

Our study compared the distribution of NPO funding across cancer types versus their respective burdens on society and explored factors that may influence which cancers receive more public support.

\section{Patients and Methods}

\section{Sample}

We used a purposive method to identify the largest cancer-related NPOs in terms of annual revenue. The sample was constructed using 2 unique methods, both using the GuideStar database of 501(c)(3) organizations. Only organizations with $\geq \$ 5$ million of annual revenue were included to focus the sample on organizations large enough to have a national impact on the broader oncology community.

First, organizations with the health-related National Taxonomy of Exempt Entities codes G ("Diseases, Disorders, Medical Disciplines") and H ("Medical Research") were selected based on the 2017 coding system. Second, the GuideStar database was queried with each of 168 predetermined search terms of cancer-related words or phrases (eg, "breast cancer" or "colon cancer"). The list of search terms is shown in supplemental eTable 1 (available with this article at JNCCN.org). We excluded non-cancer-related organizations and organizations that primarily deliver medical care (eg, acute care hospitals, outpatient clinics) based on a review of each organization's annual report, website, or mission statement. Charitable or foundation branches of acute care hospitals or cancer centers were included if their primary function is as a charity or PAO.

\section{Data Collection}

From October 2017 through February 2018, we collected and analyzed the Form 990 tax records, annual reports, and websites of each organization included in the study. Annual reports were obtained from each organization's website when available, and Form 990 reports were obtained from the organization's website or the GuideStar database, whichever was most recent. Data from July 2015 through December 2016 were included because these were the most current at the time of analysis. Annual revenue was collected from Part I, line 12 of the Form 990 tax records, and expenditures were collected from the annual report or Form 990. Expenditures were classified into 1 of 9 categories: patient support (eg, support groups, paying for transportation), patient education, research, prevention, treatment (eg, copay assistance for medications), professional education (eg, professional society conferences), policy advocacy (lobbying), administrative costs, and fundraising.

To assess disease burden on society by cancer type, we collected data on annual incidence, mortality, and person-years of life lost (PYLL) for each cancer type in 2017 (the year of study analysis) from the SEER database. ${ }^{9}$ The pediatric cancer category was defined as cancers occurring in patients aged 0 to 18 years (most commonly leukemias and brain tumors). PYLL is the difference between the actual age of death from a disease and the expected age of death for an individual (eg, a person who dies of cancer at age 35 years has more PYLL than someone who dies of cancer at age 75 years). ${ }^{10}$

\section{Statistical Analysis}

Annual revenue by cancer type was calculated using descriptive statistics. Comparison of total annual revenue by cancer type versus cancer type-specific incidence, mortality, and PYLL was performed using scatter plots. Correlation between revenue and cancer typespecific incidence, mortality, and PYLL was assessed with Pearson product-moment correlation coefficients. We assessed for correlation between increased allocation to each of the 9 expenditure categories and total annual revenue using the Pearson product-moment correlation coefficient.

We also assessed the effect of cancer association with a high-risk behavior or stigma on NPO funding. Stigma was defined as the association between a personal choice to participate in a cancer-causing behavior and a particular cancer. An association was considered strong enough for study inclusion if the hazard ratio between that behavior and an individual cancer was $\geq 2.0$ based on review of the epidemiologic literature. ${ }^{11-15}$ Included stigmatized behaviors were smoking, alcohol, intravenous drug use, sex, and tanning beds. We then compared the amount of revenue allocated to stigmatized cancers versus nonstigmatized cancers using descriptive statistics.

\section{Results}

The 2 search methods yielded 172 cancer-related NPOs, 53 of which were excluded because they were primarily medical care delivery organizations (eg, acute care hospitals or clinics), yielding 119 cancer-related NPOs included for analysis. The complete list of organizations is shown in supplemental eAppendix 1; 4 organizations supported $\geq 2$ cancer types and were counted toward each cancer type they supported.

Cancer-related NPOs generated $\$ 5.98$ billion in annual revenue in 2015 through 2016. Most of the revenue, $\$ 4.59$ billion $(76.8 \%)$, was generated by the $59(50 \%)$ 
organizations that support cancer in general with no focus on one disease (eg, American Cancer Society [ACS]). Table 1 shows the complete breakdown of number of NPOs and amount of annual revenue supporting each cancer type.

Among cancer type-specific NPOs, the cancers with the largest number of organizations were breast cancer $(13 ; 22 \%)$, pediatric cancers $(13 ; 22 \%)$, leukemia $(4 ; 7 \%)$, and lung cancer $(4 ; 7 \%)$. The cancer types with the largest total annual revenue were breast cancer ( $\$ 460$ million; $33.2 \%$ ), leukemia ( $\$ 201$ million; $14.5 \%$ ), pediatric cancers (\$177 million; 12.8\%), and lymphoma (\$145 million; $10.5 \%)$. Cancer types with only 1 NPO supporting them were neuroendocrine, nonmelanoma skin, liver and bile duct, cervical, and endometrial cancers; myelodysplastic syndromes (MDS); and sarcoma. Cancers with the lowest total annual revenue were sarcoma ( $\$ 5.1$ million; $0.4 \%$ ), endometrial cancer ( $\$ 5.4$ million; $0.4 \%$ ), cervical cancer ( $\$ 5.4$ million; 0.4\%), MDS ( $\$ 5.6$ million; $0.4 \%$ ), and liver and bile duct cancers ( $\$ 5.8$ million; $0.4 \%$ ). Notably, there were no NPOs that had at least $\$ 5$ million in annual revenue supporting kidney, bladder, gastric, or esophageal cancers.

The 2017 SEER database statistics for annual incidence, mortality, and PYLL for each cancer type that were used in this analysis are shown in supplemental eTable 2.

Scatter plots comparing the total annual revenue per cancer type with the annual incidence, number of deaths, and PYLL are shown in Figure 1. Comparison of annual revenue with incidence (Figure 1A) showed that breast cancer, leukemia, lymphoma, pediatric cancers, and neuroendocrine cancers were well funded in proportion to their incidences. Multiple myeloma appeared to be proportionally funded, whereas gastrointestinal cancers (colorectal, pancreatic, and liver and bile duct), gynecologic cancers (ovarian, endometrial, and cervical), lung cancer, prostate cancer, melanoma, MDS, sarcoma, and brain cancers were all poorly funded in proportion to their incidences. A consistent pattern emerged when comparing annual revenue with mortality (Figure 1B) and PYLL (Figure 1C), which was largely in line with the comparison between annual revenue and incidence. Breast cancer, leukemia, lymphoma, and pediatric cancers were well funded in proportion to their annual number of deaths and PYLL. All others, including gastrointestinal, gynecologic, lung, prostate, and brain cancers and melanoma, and multiple myeloma, were poorly funded in proportion to their annual number of deaths and PYLL.

The scatter plots in general showed little correlation between annual incidence, mortality, or PYLL with amount of funding for NPOs of a particular cancer type. The Pearson product-moment correlation coefficients between annual revenue and annual incidence, mortality,

\begin{tabular}{|c|c|c|}
\hline Cancer Type & $\begin{array}{c}n(\%) \\
(N=119)\end{array}$ & $\begin{array}{c}\text { Revenue (\%) } \\
\text { (N=\$6 billion) }\end{array}$ \\
\hline All types & $59(50.0)$ & $\$ 4.6$ billion (76.8) \\
\hline Breast & $13(11.0)$ & $\$ 460$ million $(7.7)$ \\
\hline Pediatric & $13(11.0)$ & $\$ 177$ million (3.0) \\
\hline Leukemia & $4(3.4)$ & $\$ 201$ million (3.4) \\
\hline Lung & $4(3.4)$ & $\$ 92$ million (1.5) \\
\hline Prostate & $3(2.5)$ & $\$ 74$ million (1.2) \\
\hline Ovarian & $3(2.5)$ & $\$ 23$ million $(0.4)$ \\
\hline Brain & $3(2.5)$ & $\$ 20$ million (0.3) \\
\hline Lymphoma & $2(1.7)$ & $\$ 145$ million (2.4) \\
\hline Pancreatic & $2(1.7)$ & $\$ 58$ million (1.0) \\
\hline Multiple myeloma & $2(1.7)$ & $\$ 51$ million (0.9) \\
\hline Colorectal & $2(1.7)$ & $\$ 18$ million $(0.3)$ \\
\hline Melanoma & $2(1.7)$ & $\$ 14$ million $(0.2)$ \\
\hline Neuroendocrine & $1(0.8)$ & $\$ 17$ million (0.3) \\
\hline Nonmelanoma skin & $1(0.8)$ & $\$ 7$ million $(0.1)$ \\
\hline Liver and bile duct & $1(0.8)$ & $\$ 5.8$ million $(0.1)$ \\
\hline Myelodysplastic syndromes & $1(0.8)$ & $\$ 5.6$ million $(0.1)$ \\
\hline Cervical & $1(0.8)$ & $\$ 5.4$ million (0.1) \\
\hline Endometrial & $1(0.8)$ & $\$ 5.4$ million $(0.1)$ \\
\hline Sarcoma & $1(0.8)$ & $\$ 5.1$ million $(0.1)$ \\
\hline Annual Revenue (millions, \$) & \multicolumn{2}{|c|}{ n (\%) } \\
\hline $5.0-24.9$ & \multicolumn{2}{|c|}{$96(71)$} \\
\hline $25.0-49.9$ & \multicolumn{2}{|c|}{$19(14)$} \\
\hline $50.0-74.9$ & \multicolumn{2}{|c|}{$3(2)$} \\
\hline $75.0-99.9$ & \multicolumn{2}{|c|}{$6(4)$} \\
\hline $100.0-124.9$ & \multicolumn{2}{|c|}{$2(1)$} \\
\hline $125.0-149.9$ & \multicolumn{2}{|c|}{$3(2)$} \\
\hline $150.0-174.9$ & \multicolumn{2}{|c|}{$1(1)$} \\
\hline 175.0-199.9 & \multicolumn{2}{|c|}{$0(0)$} \\
\hline $200.0-249.9$ & \multicolumn{2}{|c|}{$0(0)$} \\
\hline $250.0-299.9$ & \multicolumn{2}{|c|}{$1(1)$} \\
\hline $300.0-399.9$ & \multicolumn{2}{|c|}{$2(1)$} \\
\hline 400.0-499.9 & \multicolumn{2}{|c|}{$0(0)$} \\
\hline $500.0-749.9$ & \multicolumn{2}{|c|}{$1(1)$} \\
\hline 750.0-999.9 & \multicolumn{2}{|c|}{$2(1)$} \\
\hline$\geq 1,000.0$ & \multicolumn{2}{|c|}{$0(0)$} \\
\hline
\end{tabular}

and PYLL were $0.61,0.16$, and 0.16 , respectively. These indicate that there may be a weak correlation between annual revenue and cancer type-specific incidence, but there is essentially no correlation between annual revenue and cancer type-specific mortality or PYLL.

Analysis for correlation of different spending priorities on annual revenue showed that increased spending 
A

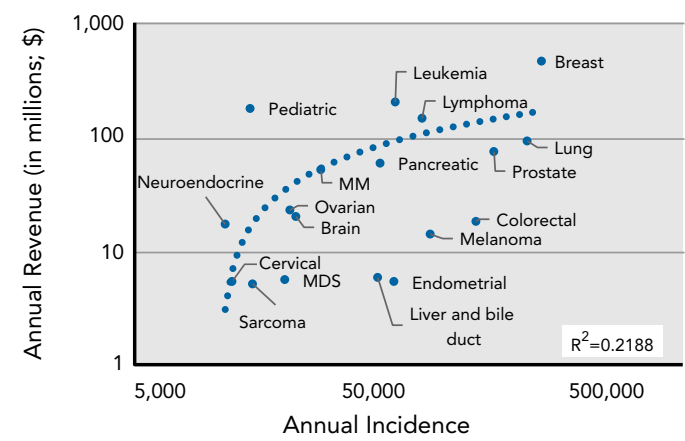

B

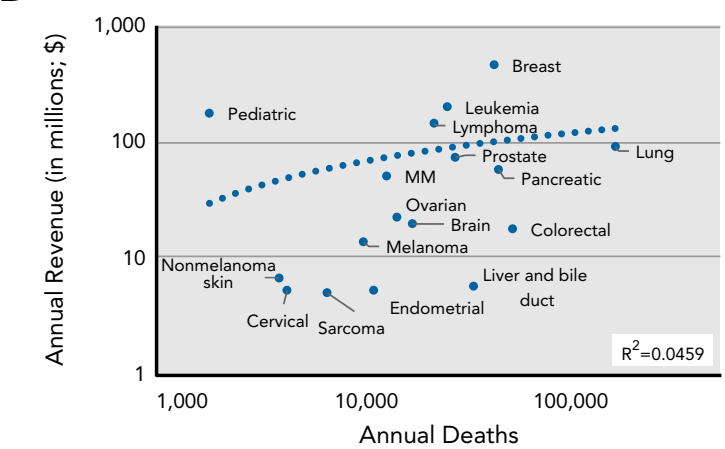

C

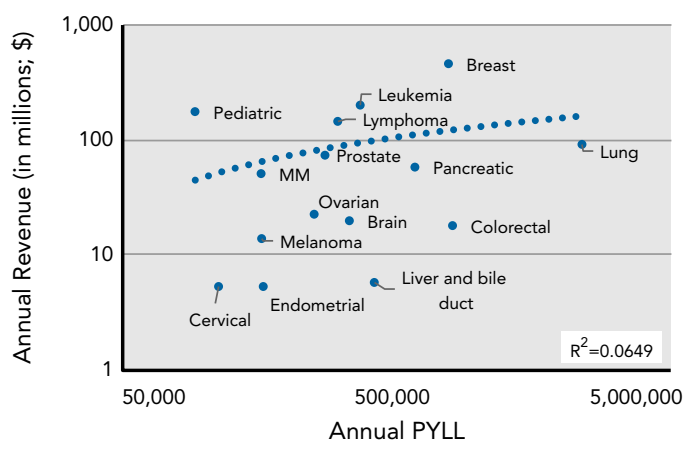

Figure 1. Scatter plots using logarithmic scales for annual revenue by cancer type versus annual $(A)$ incidence, $(B)$ mortality, and $(C)$ PYLL. Logarithmic trendlines and $\mathrm{R}^{2}$ values are displayed in each panel.

Abbreviations: MDS, myelodysplastic syndromes; MM, multiple myeloma; PYLL, person-years of life lost.

on fundraising and administrative costs was the most highly correlated with higher annual revenue, with Pearson correlation coefficients of 0.99 and 0.97 , respectively. In addition, 4 of the top 5 histologies in terms of spending on fundraising were also in the top 5 for annual revenue. Conversely, 4 of the bottom 5 histologies in terms of spending on fundraising were also in the lowest 5 for annual revenue. Increased spending on research funding, patient education, and patient treatment was also highly correlated with higher annual revenue, with Pearson correlation coefficients of $0.94,0.93$, and 0.93 , respectively. Spending on professional education such as physician/researcher conferences, or policy advocacy such as political lobbying was poorly correlated with annual revenue, with Pearson correlation coefficients of 0.27 and 0.06 , respectively. A full listing of Pearson correlation coefficients between annual revenue and each of the 9 expenditure categories is shown in Table 2.

Evaluation of the literature for cancers strongly associated with high-risk, stigmatized behaviors identified 7 malignancies: lung (smoking), head and neck (smoking, alcohol), bladder (smoking), esophageal (smoking, alcohol), liver (alcohol, intravenous drug use), cervical (sex), and nonmelanoma skin cancers (tanning beds). ${ }^{1-15}$ All 7 were poorly funded in at least one epidemiologic metric, and all but skin cancer were poorly funded in all 3 metrics (incidence, mortality, and PYLL). Conversely, 14 malignancies had no strong association with a stigmatized behavior: leukemia, lymphoma, multiple myeloma, sarcoma, melanoma, and breast, pediatric, neuroendocrine, colorectal, pancreas, prostate, ovarian, endometrial, and brain cancers. ${ }^{8}$ The 4 cancer types that were well funded across all 3 metrics (breast cancer, leukemia, lymphoma, and pediatric cancers) all fell into this category. Neuroendocrine cancers were well funded compared with their incidence and were not evaluated for mortality or PYLL because these data are not known.

\section{Discussion}

It is clear that with nearly $\$ 6$ billion in annual revenue, cancer-related NPOs have an important role in funding medical research, supporting and educating patients and their families, and influencing health policy. This figure also demonstrates how deeply invested society is in cancer research and advocacy. However, our data show that this investment is not equitable across all cancer types and that the disease burden by cancer type does not correlate with the amount of NPO funding for a particular cancer. There is a weak association between increased incidence of a particular cancer type and funding for NPOs supporting that cancer, but essentially no correlation between mortality or PYLL and NPO funding. Many common or highly lethal diseases, including lung, colorectal, pancreatic, ovarian, and endometrial cancers, are underfunded relative to their burdens on society. Underfunding may have negative downstream effects on research, novel drug development, and number of FDA drug approvals for poorly funded cancers.

Our data show that increased spending on fundraising, administrative costs, and patient education to inform and energize the public about a cause correlates with increased revenue. Whether this is because 


\begin{tabular}{|lc|}
\hline \begin{tabular}{c} 
Table 2. Correlation $\begin{array}{c}\text { Between Area of Expenditure } \\
\text { and Annual Revenue }\end{array}$ \\
\hline Area of Expenditure
\end{tabular} & Pearson Correlation Coefficient \\
\hline Fundraising & 0.99 \\
\hline Administrative costs & 0.97 \\
\hline Research & 0.94 \\
\hline Patient education & 0.93 \\
\hline Patient treatment & 0.93 \\
\hline Prevention & 0.82 \\
\hline Patient support & 0.54 \\
\hline Professional education & 0.27 \\
\hline Policy advocacy & 0.06 \\
\hline
\end{tabular}

organizations with higher revenue can afford to spend more on these efforts or because increased fundraising and patient education spending leads to more revenue is unknown.

Individual donors are motivated by several factors when they choose which causes to support. Association with high-risk behaviors, such as smoking or alcohol abuse, seems to be an important factor leading to decreased funding for stigmatized cancers. However, many common or deadly cancers with no association with a stigmatized behavior were still poorly funded according to our findings, indicating that there are other relevant factors. Many donors choose a cause they are affected by, either personally or through family or friends. ${ }^{1,8}$ Marketing and social media campaigns, such as the pink ribbon representing breast cancer awareness, can increase overall public awareness of a disease and thereby increase donations. ${ }^{16}$ Diseases that are common but with indolent courses or relatively low mortality rates also have more survivors who can later become advocates for the cause and attract more donors.

The greatest limitation of this study is that most charitable dollars, nearly $\$ 4.6$ billion, go to NPOs that support all cancers, and it is unknown which diseases receive this money and in what proportion. These organizations may increase support for poorly funded causes ("crowding out"), build on already well-funded causes ("crowding in"), or act independently. ${ }^{8}$ This analysis also does not account for the NCI's funding distribution across cancer subtypes, which represents a large source of research dollars. However, a 2012 study that examined NCI funding distribution compared with cancer burden showed that breast, prostate, and brain cancers and leukemia were well funded, whereas colorectal, pancreatic, liver and bile duct, endometrial, and bladder cancers were poorly funded. ${ }^{17}$ Based on these data, it is unlikely that NCI funding would offset the NPO funding pattern illustrated in our study. Additional data from the National Cancer Research Institute in the United Kingdom showed a pattern of disproportionate funding across cancer subtypes compared with their societal burden similar to what our study showed for US NPOs. ${ }^{18,19}$

\section{Conclusions}

The goal of our study was not to divert funding away from any disease but rather to educate the public and augment charitable funding for diseases that do not receive proportionate support. Well-funded NPOs should be applauded for their successes and could collaborate with other organizations to improve funding. No one entity can fully support research and patient advocacy. Multiple different groups from government, industry, academic institutions, and philanthropic organizations are necessary. These data could help inform the funding allocations of large, general cancer NPOs and governmental entities such as ACS or the NCI and inform individual donors and grant-makers.

We hope these findings stimulate further discussion and research to explore the granular aspects of NPO funding, enabling stakeholders to make evidence-based decisions for optimal allocation.

Submitted November 15, 2018; accepted for publication February 4, 2019.

Author contributions: Study concept: All authors. Data collection: Kamath. Manuscript preparation: All authors.

Disclosures: Dr. Benson has disclosed that he is a scientific advisor for Astellas, Infinity Pharmaceuticals, Merck Sharpe \& Dohme, Genentech, Bristol-Myers Squibb, Guardant Health, Eli Lilly and Company, Exelixis, Purdue Pharma, Xcenda, InVentiv Health, Axio, Bayer, Merck, Rafael Pharmaceuticals, Terumo, and Sanofi; receives grant/research funding from Novartis, Bristol-Myers Squibb, Merck Sharp \& Dohme, Celgene, Acerta Pharmaceuticals, Advanced Accelerator Applications, and Taiho Pharmaceuticals; and serves on the Editorial Board for Emron. The remaining authors have not received any financial consideration from any person or organization to support the preparation, analysis, results, or discussion of this article.

Correspondence: Suneel D. Kamath, MD, Department of Medicine, Division of Hematology/Oncology, Northwestern University Feinberg School of Medicine, 676 North St. Clair Street, Suite 850, Chicago, IL 60611. Email: Suneel.kamath@northwestern.edu

\section{References}

1. Murciano-Goroff YR. Philanthropic partnerships and the future of cancer research. Nat Rev Cancer 2015;15:125-129.

2. Rose SL. Patient advocacy organizations: institutional conflicts of interest, trust, and trustworthiness. J Law Med Ethics 2013;41: 680-687.

3. McCoy MS, Carniol M, Chockley K, et al. Conflicts of interest for patient-advocacy organizations. N Engl J Med 2017;376: 880-885

4. Giving USA. See the numbers-Giving USA 2019 infographic. Available at: https://givingusa.org/. Accessed June 20, 2019. 
5. Abola MV, Prasad V. Industry funding of cancer patient advocacy organizations. Mayo Clin Proc 2016;91:1668-1670.

6. Rothman SM, Raveis VH, Friedman A, et al. Health advocacy organizations and the pharmaceutical industry: an analysis of disclosure practices. Am J Public Health 2011;101:602-609.

7. Clemence M, Gilby N, Shah J, et al. Wellcome Trust Monitor Wave 2: tracking public views on science, biomedical research and science education. London, UK: Wellcome Trust: May 2013. Available at: https://wellcome.ac.uk/sites/default/files/monitor-wave2-full-wellcomemay13.pdf. Accessed June 20, 2019.

8. Shah KK, Sussex J, Hernandez-Villafuerte K. Government and charity funding of cancer research: public preferences and choices. Health Res Policy Syst 2015;13:38.

9. Noone AM, Howlader N, Krapcho M, et al. SEER Cancer Statistics Review, 1975-2015, National Cancer Institute. Bethesda, MD. Available at: https:// seer.cancer.gov/csr/1975 2015/, based on November 2017 SEER data submission, posted to the SEER web site, April 2018. Accessed March 13, 2019

10. Arias E. United States Life Tables, 2011. Natl Vital Stat Rep 2015;64:1-63.

11. Alberg AJ, Samet JM. Epidemiology of lung cancer. Chest 2003; 123(Suppl):21S-49S.

12. Fattovich G, Stroffolini T, Zagni I, et al. Hepatocellular carcinoma in cirrhosis: incidence and risk factors. Gastroenterology 2004;127(Suppl):S35-50.
13. Prabhu A, Obi KO, Rubenstein $\mathrm{JH}$. The synergistic effects of alcohol and tobacco consumption on the risk of esophageal squamous cell carcinoma: a meta-analysis. Am J Gastroenterol 2014;109:822-827.

14. Franco EL, Schlecht NF, Saslow D. The epidemiology of cervical cancer Cancer J 2003;9:348-359.

15. Freedman ND, Abnet CC, Caporaso NE, et al. Impact of changing US cigarette smoking patterns on incident cancer: risks of 20 smoking-related cancers among the women and men of the NIH-AARP cohort. Int $\mathrm{J}$ Epidemiol 2016;45:846-856.

16. Harvey JA, Strahilevitz MA. The power of pink: cause-related marketing and the impact on breast cancer. J Am Coll Radiol 2009;6:26-32.

17. Carter AJ, Nguyen CN. A comparison of cancer burden and research spending reveals discrepancies in the distribution of research funding. BMC Public Health 2012;12:526.

18. Burnet NG, Jefferies SJ, Benson RJ, et al. Years of life lost (YLL) from cancer is an important measure of population burden-and should be considered when allocating research funds. Br J Cancer 2005; 92:241-245.

19. Carter AJ, Delarosa B, Hur H. An analysis of discrepancies between United Kingdom cancer research funding and societal burden and a comparison to previous and United States values. Health Res Policy Syst 2015;13:62

\title{
Explore Oncology From Every Angle
}

\author{
The Hub for Disease-Specific Clinical Information \\ $\checkmark$ JNCCN Spotlights: \\ $>$ Links to professional \\ exclusive commentary \\ and patient resources \\ about current therapies \\ $>$ Summaries of News \\ Video interviews with experts \\ and Literature
}

JNCCN360.org

\$IARBORSIDE

The nexus of knowledge

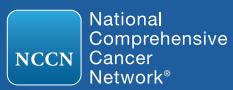


Supplemental online content for:

\section{Comparison of Cancer Burden and Nonprofit Organization Funding Reveals Disparities in Funding Across Cancer Types}

Suneel D. Kamath, MD; Sheetal M. Kircher, MD; and Al B. Benson III, MD

J Natl Compr Canc Netw 2019;17(7):849-854

eTable 1: List of Cancer-Related Search Terms

eTable 2: Cancer Burden by Cancer Type in 2017

eAppendix 1: List of Included NPOs and PAOs 


\section{eTable 1. List of Cancer-Related Search Terms}

\begin{tabular}{|c|c|c|c|}
\hline Cancer & Cure & Tongue cancer & Peritoneum \\
\hline Blood cancer & Small cell & Small bowel cancer & Peritoneal \\
\hline Tumor & Unknown primary & Small intestine cancer & Chondrosarcoma \\
\hline Oncology & Urothelial cancer & Small intestinal cancer & Parotid gland \\
\hline Carcinoma & Transitional cell & Large intestine cancer & Salivary gland \\
\hline Breast & Ureter cancer & Large bowel cancer & Neurologic cancer \\
\hline Lung & Ureteral cancer & Large intestinal cancer & Retina \\
\hline Prostate & Urethra cancer & Vagina & Testis \\
\hline Bladder & Urethral cancer & Fallopian tube & Testis cancer \\
\hline Brain & Vaginal cancer & Biliary & Testicle \\
\hline Brain tumor & Waldenström & Cutaneous & Adrenal \\
\hline Glioma & Waldenström's & Myeloid & Teratoma \\
\hline Glioblastoma & Wilms & Lymphocyte & Basal cell \\
\hline Throat & Angiosarcoma & Lymphoid & Embryonal \\
\hline Oral cancer & Squamous & Astrocytoma & Germ cell \\
\hline Esophagus & Esophageal & Soft tissue & Intraocular \\
\hline Stomach & Bile duct & Bronchus cancer & Ependymoma \\
\hline Gastric & Gallbladder & Bronchial cancer & Stromal \\
\hline Pancreas & Cholangiocarcinoma & Pulmonary & GIST \\
\hline Pancreatic & Liver & Eye cancer & Uvea \\
\hline Colon & Hepatocellular & Ocular & Uveal \\
\hline Rectal & Marrow & Tonsil & Nerve sheath \\
\hline Sarcoma & Kaposi & Ewing & Ewing's \\
\hline Kidney & Renal cell & Kaposi's & Heart tumor \\
\hline Cervical & Penile & Testicular & Islet cell tumor \\
\hline Ovarian & Penis & Ductal & Lip cancer \\
\hline Leukemia & Sezary & Mycosis & Merkel cell \\
\hline Lymphoma & Hodgkin & Non-Hodgkin & Plasma cell \\
\hline Myeloma & Hodgkin's & Non-Hodgkin's & Nasal \\
\hline Melanoma & Skin cancer & Synovial & Nasopharyngeal \\
\hline Skin & Rhabdomyosarcoma & Retinoblastoma & Paraganglioma \\
\hline Bone cancer & Osteosarcoma & Spine cancer & Spinal cancer \\
\hline Pediatric cancer & Medulloblastoma & Spine tumor & Spinal tumor \\
\hline Children & Neuroblastoma & Liposarcoma & Parathyroid \\
\hline Neuroendocrine & Carcinoid & Leiomyosarcoma & Pheochromocytoma \\
\hline Colorectal & Mouth cancer & Cervix & Pituitary \\
\hline Ampullary cancer & Vulvar cancer & Ovary & Oropharyngeal cancer \\
\hline Uterine cancer & Endometrial cancer & Myelodysplastic & Thyroid \\
\hline Anal & Anus & Myelodysplasia & Thymoma \\
\hline Head and neck & Mesothelioma & Myeloproliferative & Neoplasm \\
\hline Laryngeal & Larynx & Polycythemia & Thrombocytosis \\
\hline Pharyngeal & Pharynx & Cord blood & Adenocarcinoma \\
\hline
\end{tabular}

Abbreviation: GIST, gastrointestinal stromal tumor. 


\section{eTable 2. Cancer Burden by Cancer Type in 2017}

\begin{tabular}{|lrrc|}
\hline Type & Incidence & Deaths & PYLL \\
\hline Brain & 23,800 & 16,700 & 336,000 \\
\hline Breast & 255,180 & 41,070 & 773,000 \\
\hline Cervical & 12,820 & 4,210 & 112,000 \\
\hline Colorectal & 135,430 & 50,260 & 800,000 \\
\hline Endometrial & 61,380 & 10,920 & 163,000 \\
\hline Leukemia & 62,130 & 24,500 & 368,000 \\
\hline Liver and bile duct & 52,450 & 32,750 & 415,000 \\
\hline Lymphoma & 80,500 & 21,210 & 305,000 \\
\hline Lung & 222,500 & 155,870 & $2,372,000$ \\
\hline Myelodysplastic syndromes & 21,338 & $\mathrm{NA}$ & $\mathrm{NA}$ \\
\hline Melanoma & 87,110 & 9,730 & 161,000 \\
\hline Multiple myeloma & 30,280 & 12,590 & 160,000 \\
\hline Neuroendocrine & 12,000 & $\mathrm{NA}$ & $\mathrm{NA}$ \\
\hline Ovarian & 22,440 & 14,080 & 250,000 \\
\hline Pancreatic & 53,670 & 43,090 & 583,000 \\
\hline Pediatric & 15,270 & 1,790 & 92,000 \\
\hline Prostate & 161,360 & 26,730 & 274,000 \\
\hline Sarcoma & 15,650 & 6,540 & $\mathrm{NA}$ \\
\hline Nonmelanoma skin & 8,250 & 3,860 & $\mathrm{NA}$ \\
\hline Sbreviation & &
\end{tabular}

Abbreviations: NA, not available; PYLL, person-years of life lost. 


\section{eAppendix 1: List of Included NPOs and PAOs}

\section{All Cancers}

Alliance for Clinical Trials in Oncology Foundation

American Association for Cancer Research (AACR)/AACR

Foundation

American Cancer Society (ACS)/ACS Cancer Action Network/ACS Products/ACS of Puerto Rico

American Institute for Cancer Research

American Society for Radiation Oncology

ASCO

Bay Area Tumor Institute

Beckman Research Institute of the City of Hope

Biomed Valley Corporation

Camp Kesem National

Canadian Cancer Society

Cancer Care Co-Payment

Assistance Foundation

Cancer Care Incorporated

Cancer Prevention Institute of California

Cancer Research and Biostatistics

Cancer Research Fund of the Damon Runyon-Walter Winchell Foundation

Cancer Research Institute

Cancer Support Community

Chronic Disease Fund

Coalition of Cancer Cooperative Groups
Commonwealth Foundation for Cancer Research Foundation

Conquer Cancer Foundation of ASCO

Dolphins Cycling Challenge

Don't Ever Give Up/The V

Foundation

ECOG-ACRIN Medical Research Foundation

H. Lee Moffitt Cancer Center and Research Institute Foundation/H. Lee Moffitt Cancer Center and Research Institute Lifetime Cancer Screening Center

Health Research Incorporated

The Hope Foundation

Huntsman Cancer Foundation

Institute for Cancer Research

Israel Cancer Research Fund

John Wayne Cancer Institute

Jonsson Cancer Center

Foundation-UCLA

The Livestrong Foundation

Louisiana Cancer Research Center of LSU Health Sciences Center in New Orleans

Ludwig Institute for Cancer Research (LICR)/LICR Fund

Mary Crowley Medical Research Center

NCCN

National Foundation for Cancer Research
NRG Oncology Foundation

Oncology Nursing Society

Pan Massachusetts Challenge Trust

Parker Institute for Cancer Immunotherapy

Patient Access Network Foundation

Pedal the Cause

Personal Care Products Council Foundation

Prevent Cancer Foundation

Rofeh Cholim Cancer Society

Roswell Park Alliance Foundation

RTOG Foundation

Sanford Burnham Prebys Medical Discovery Institute

Society of Surgical Oncology

Translation Research in Oncology US

Union for International Cancer Control

United Cancer Support Foundation University of Tennessee West Institute for Cancer Research

UT Southwestern Moncrief Cancer Institute

Van Andel Research Institute Walker Cancer Research Institute Wistar Institute of Anatomy \& Biology 
4 - Kamath et al

\section{eAppendix 1: List of Included NPOs and PAOs (cont.)}

\begin{tabular}{l}
\hline Brain Cancer \\
American Brain Tumor Association \\
Ben and Catherine Ivy Foundation \\
National Brain Tumor Society \\
\hline Breast Cancer
\end{tabular}

Avon Products Foundation

Breast Cancer Charities of America

Breast Cancer Outreach

Foundation

Breast Cancer Research

Foundation

The Breast Cancer Society

Community Charity Advancement Incorporated

Living Beyond Breast Cancer

National Breast Cancer

Foundation

NSABP Foundation

Quantum Leap Healthcare Collaborative

The Rose

The Susan G. Komen Breast Cancer Foundation

Windber Research Institute

Cervical Cancer

The GOG Foundation

Colorectal Cancer
Colon Cancer Alliance
NSABP Foundation

\begin{tabular}{|l|}
\hline Endometrial Cancer \\
The GOG Foundation \\
\hline Prostate Cancer \\
\hline
\end{tabular}

Movember Foundation

Prostate Cancer Foundation

Zero-The End of Prostate Cancer

$$
\begin{aligned}
& \text { Leukemia } \\
& \text { Be the Match Foundation } \\
& \text { DKMS } \\
& \text { Gift of Life Marrow Registry } \\
& \text { The Leukemia \& Lymphoma } \\
& \text { Society }
\end{aligned}
$$

\section{Liver and Bile Duct Cancers}

Baruch S. Blumberg Institute

\section{Lymphoma \\ The Leukemia \& Lymphoma Society \\ Lymphoma Research Foundation}

Lung Cancer

American Lung Association

Bonnie J. Addario Lung Cancer Foundation

International Association for the Study of Lung Cancer

LUNGevity Foundation

\section{Myelodysplastic Syndromes}

Aplastic Anemia and MDS

International Foundation

\begin{tabular}{l}
\hline Melanoma \\
Melanoma Research Alliance \\
Melanoma Research Foundation \\
\hline Multiple Myeloma \\
International Myeloma \\
Foundation \\
Multiple Myeloma Research \\
Foundation \\
\hline Sarcoma \\
SARC
\end{tabular}

Neuroendocrine Cancers

Neuroendocrine Tumor Research Foundation

\section{Ovarian Cancer \\ The GOG Foundation \\ National Ovarian Cancer Coalition \\ Ovarian Cancer Research Fund Alliance}

\section{Pancreatic Cancer}

Marc Lustgarten Pancreatic Cancer Foundation

Pancreatic Cancer Action Network

\section{Pediatric Cancers}

Alex's Lemonade Stand Foundation

Alliance for Childhood Diseases

Children's Cancer Recovery Foundation

Children's Cancer Research Fund

Children's Oncology Group

Foundation

Children's Tumor Foundation

Cure Childhood Cancer

CureSearch for Children's Cancer

Hyundai Hope on Wheels

The National Children's Cancer Society

Pediatric Brain Tumor Foundation of the United States

St. Baldrick's Foundation

Valerie Fund

\section{Skin Cancer}

The Skin Cancer Foundation

Abbreviations: NPO, nonprofit organization; PAO, patient advocacy organization. 